\title{
Off to a good start: Publishing the first volume
}

\author{
Otis Crandell \\ Babeș-Bolyai University, Geology Department, Cluj-Napoca, Romania. Email: otis.crandell@ubbcluj.ro
}

The journal is off to a very good start. In this first volume we have published a total of thirty four articles - twenty six research articles, two summary and synthesis articles, one biography, two book reviews, and three event reviews. Already we have several more articles that are being prepared for the upcoming second volume and we have several special issues planned for 2015. I would like to express my sincere gratitude to the Editorial Board, the technical editors, and the reviewers who contributed their time and expertise and, most of all, the authors themselves.

This issue we have a nice variety of topics presented. Geographically most are from Europe, but we also have our first article from South America, and an article regarding finds from Mesopotamia. In fact, the article about Mesopotamia is also our first article related to gemology or decorative stone objects. The article by Aimola et al. is very interesting in that it presents finds from one of the earliest occupied sites in Brazil and some of the artefacts themselves are associated with layers that pre-date the main peopling of the Americas and thus makes a valuable contribution to the discussion of the when the New World was first populated. Tarriño et al. have provided us with updates on the research at the Treviño flint mines in Spain. This research is of particular importance not only because it is one of the few prehistoric flint mines on the Iberian Peninsula but also because it gives us a general look into the early stages of the Chaîne opératoire of knapped stone industries. Most of the research articles in this issue were based on presentations from the International Symposium on Chert and other Knappable Materials which was held in Iasi, Romania in the summer of 2013.

On the topic of symposia, we would like to take this opportunity to remind our readers about two up-coming events in 2015 whose proceedings will be published in JLS. The first is the international Ground Stone Artifacts and Society workshop in July, at the University of Haifa, Israel. The second is the International Symposium on Knappable Materials 'On the Rocks' hosted this time by the University of Barcelona, in September.

As some of you will have noticed, in this issue we have started publishing book and event reviews. The journal's website also contains a list of books that were recommended for review. JLS is open to publishing reviews of any books that are about a lithics related topic or which contain a large number of articles related to lithics research. We are particularly interested in reviews of non-English books as we feel that this will help to disseminate local or regional research to a wider audience. Likewise we are interested in publishing reviews of lithics related events including symposia, training workshops, and public demonstrations. If you have attended an interesting event, we would like to hear about it.

Published by the School of History, Classics and Archaeology, University of Edinburgh ISSN: 2055-0472. URL: http://journals.ed.ac.uk/lithicstudies/

This work is licensed under a Creative Commons Attribution 2.5 UK: Scotland License. 
If you are interested in writing an article, report or review, please let us know. Although issues are released twice a year, the individual articles are published on an ongoing basis as soon as they have been reviewed, revised and accepted.

As mentioned previously, JLS is run by a staff of volunteers. If you feel that you have the time, a relevant skill or an interest in the technical side of publishing, send us a message to introduce yourself and tell us about your interest in volunteering.

Until our next issue, I would like to thank everyone again for their contributions to our success and wish you all good luck in your research. I look forward to reading about it perhaps here in the Journal of Lithic Studies.

Otis Crandell

Editor-in-Chief Journal of Lithic Studies 